\title{
Effectiveness of Acceptanceand Commitment Therapy and Logotherapy on Happiness of Veterans' Spouses
}

\section{A R T I C L E I N F O}

\section{Article Type}

Original Research

\section{Authors}

Falahati M. ${ }^{1} M A$,

Shafiabady A. ${ }^{* 2} P h D$,

Jajarmi M. ${ }^{1} \mathrm{PhD}$,

Mohamadipoor M. ${ }^{3} \mathrm{PhD}$

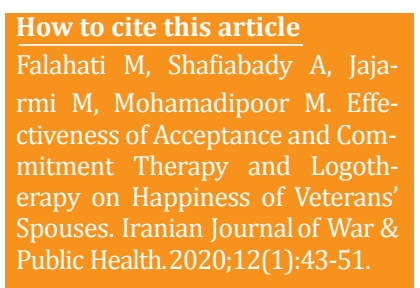

${ }^{1}$ Psychology Department, Humanities Faculty, Bojnord Branch, Islamic Azad University, Bojnord, Iran ${ }^{2}$ Counseling Department, Education \& Psychology Faculty, Allameh Tabatabaei University, Tehran, Iran

${ }^{3}$ Psychology Department, Humanities Faculty, Quchan Branch, Islamic Azad University, Quchan, Iran

\section{*Correspondence}

Address: Counseling Department, Education \& Psychology Faculty, Allameh Tabatabaei University, Dehkade-ye Olampik, West Hemmat Highway, Tehran, Iran. Postal code: 1489684511

Phone: -

Fax: -

ashafiabady@yahoo.com

\section{Article History}

Received: July 30, 2019

Accepted: January 11, 2020

ePublished: March 17, 2020

\section{A B S T R A C T}

Aims Happiness is one of the most important mental needs of mankind which has a major impact on personality and mental health. The aim of this study was to investigate the effectiveness of acceptance and commitment therapy and Logotherapy on happiness of veterans' spouses.

Materials \& Methods In this semi experimental study with pretest-posttest design, with two case groups and one witness group, 60 people of veterans' spouses were studied in Tehran in 2017. The subjects were selected using simple random sampling method and were randomly assigned into acceptance and commitment therapy, Logotherapy and witness group ( $n=20$ in each group). Case groups were treated in 9 sessions in 120 minutes and the witness group received no cure. The research tools were a demographic questionnaire and oxford happiness questionnaire. Data were analyzed using SPSS 18 software, through oneway analysis of covariance and Tukey's post hoc test.

Findings By controlling the effects of pretest scores, there was a significant difference between the mean scores of happiness of the groups in the posttest step $(F=10.827 ; p<0.001)$. The mean scores of happiness in the acceptance and commitment therapy group $(\mathrm{p}<0.001)$ and the Logotherapy group ( $p=0.008)$ had significant difference in comparison to the witness group. There was no significant difference between two case groups and both methods had the same effectiveness ( $\mathrm{p}>0.05)$.

Conclusion Both acceptance and commitment therapy and Logotherapy are effective in increasing the happiness of veterans' spouses.

Keywords Acceptance and Commitment Therapy; Logotherapy; Happiness; Veterans; Spouses

\section{I T A T I O N L I N K S}

[1] Military-related post-traumatic stress ... [2] Correlation of social support with social ... 3] The relationship among depression ... [4] Psychological and marital distress in ... [5] Level of expressed emotion, depression ... [6] Influence of individual, familial and ... [7] The comparison of the quality of life of the ... [8] The effectiveness of training coping ... [9] Effectiveness of solution-focused brief ... [10] Happiness strategies among ... [11] Subjective well-being: three decades ... [12] Is valuing happiness associated with ... [13] The effects of solution- focused psychotherapy ... [14] Climbing our hills: a beginning conversation ... [15] The role of psychological interventions ... [16] Acceptance and commitment ... [17 Acceptance and commitment therapy ... [18] An acceptance-based behavioral therapy .. [19] What is acceptance and commitment ... [20] Outcomes of religious and spiritual adaptations ... [21] Theory and practice in group ... [22] Hope and the meaning of life as ... [23] Victor Frankl's logotherapy: spirituality ... [24] Effectiveness of acceptance ... [25] The Efficacy of acceptance and commitment ... [26] Effectiveness of acceptance and commitment ... [27] A review of acceptance and commitment ... [28] The effectiveness of group-based ... [29] The impact of group counseling in logo therapy ... [30] The effect of logotherapy on the suffering ... [31] The concept and measurement ... [32] Family caregiving for patients with stroke ... [33] The importance of sample size ... [34] Happiness as a function of personality ... [35] Does status in consistency matter for ... [36] A preliminary evaluation of the ... [37] Reliability and validity of the Oxford ... [38] Effectiveness of solution-focused ... [39] Acceptance and commitment therapy ... [40] Man's search for meaning ... [41] Comparison the effectiveness of solution ... [42] Cognitive defusion and self ... [43] Mindfulness and acceptance approaches ... [44] Effectiveness of acceptance- and commitment ... [45] Meaning of life and meaning of ... [46] Meaning in life and non-suicidal self ... [47] Meaning in Life and Health: Proactive ... [48] Strategies used in coping with a cancer ... 
تجربهشده توسط فرد مراقب است كه ناشى از اختلال در فعاليتهاى

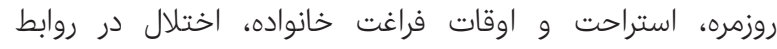

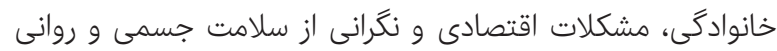

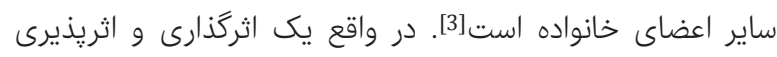
دوطرفه بين شرايط بيمار و مراقب او ديده مىشود [4]، بهاطورى كه

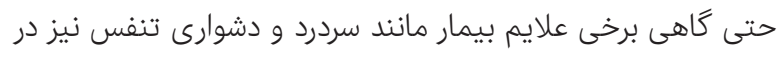

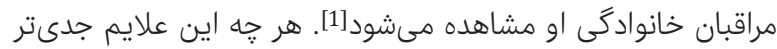

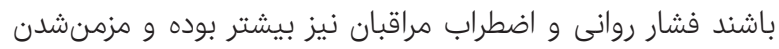

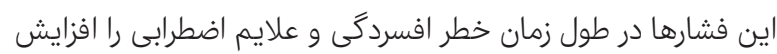

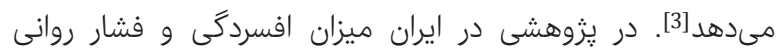

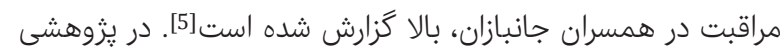

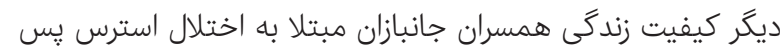

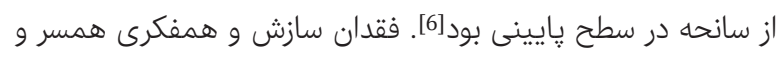

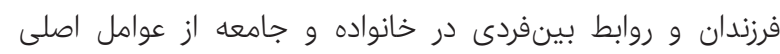

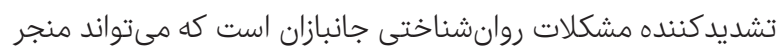

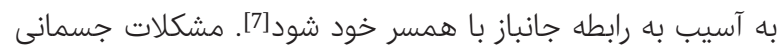
و روانى بر سازگارى و نظام خانواده موثر بوده و كنشهائ جناى جديدى

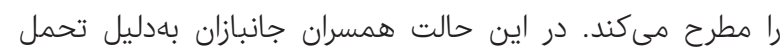

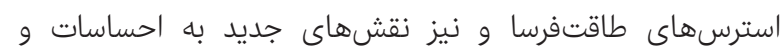

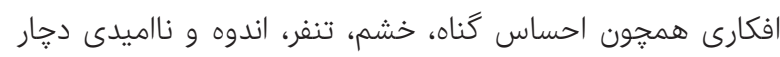
شده و شادكامى آنها مختل مىشود احساه

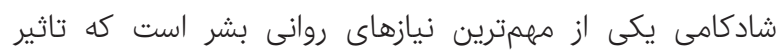

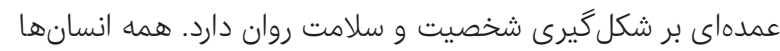

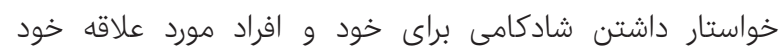

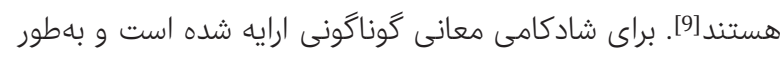

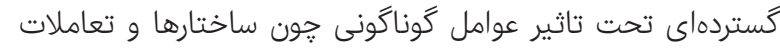

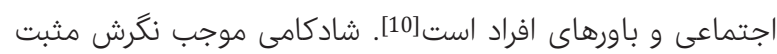

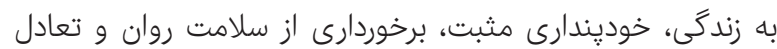

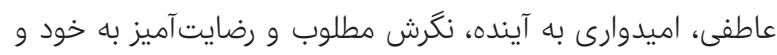

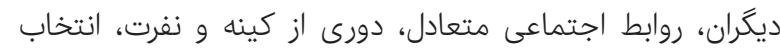

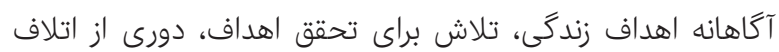

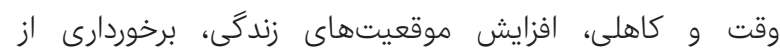

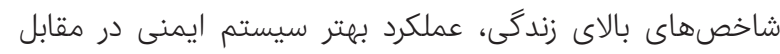
استرسها، خواب بهتر، تمايل بيشتر در كمك به به ديكران، عملكرد

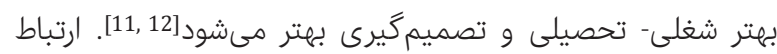

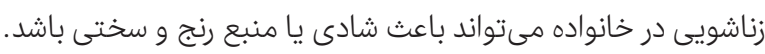

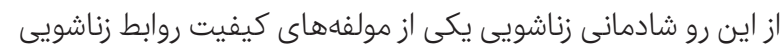

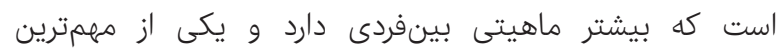

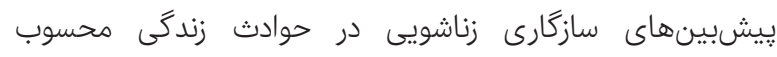
مى شود [13].

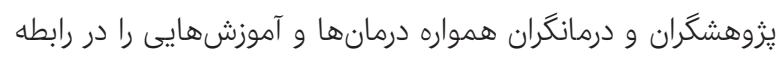

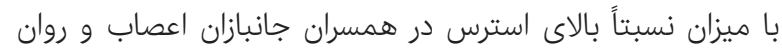

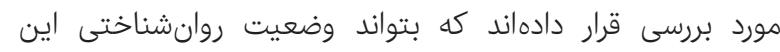
همسران را بهبود بخشد، بدين خاطر استفاده از روشهايى كه

\section{اثربخشى درمان مبتنى بر ڤذئيرش و و تعهد و معنادرمانى بر شادكامى همسران جانبازان}

\author{
MA مريم فلاحتى \\ كروه روانشناسى، دانشكده علوم انسانى، واحد بجنورد، دانشكاه آزاد اسلامى، \\ بجنورد، ايران

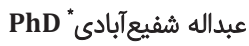

كروه مشاوره، دانشكده روانشناسى و و علوم تربيتى، دانشگاه علامه طباطبايى، تهران، ايران

محمود جاجرمى PhD كَره روانشناسى، دانشكده علوم انسانى، واحد بجنورد، دانشكاه آزاد اسلامى، بجنورد، ايران

محمد محمدىيور PhD كَروه روانشناسى، دانشكده علوم انسانى، واحد قوجٍان، دانشكاه آزاد اسلامى، قوجان، ايران

جكيده اهداف: شادكامى يكى از مهمترين نيازهاى روانى بشر است كه تاثير عمداى بر

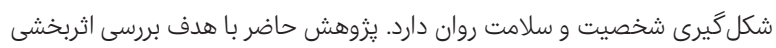

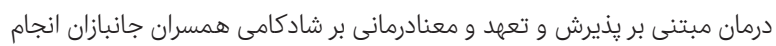

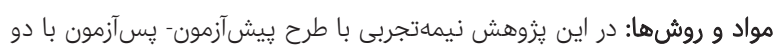

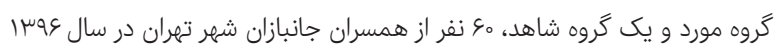

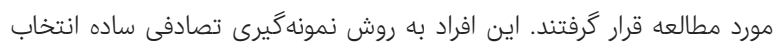

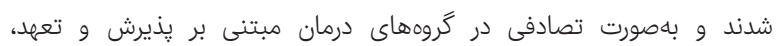

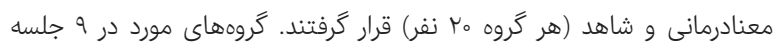

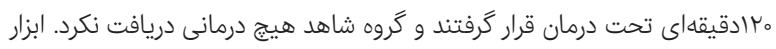

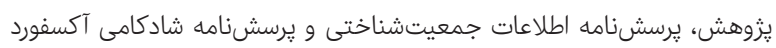

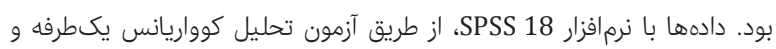

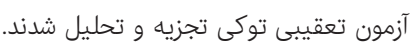

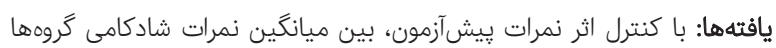

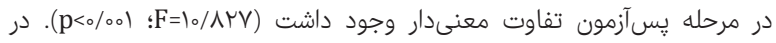

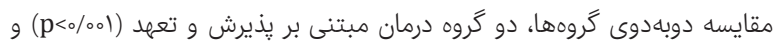

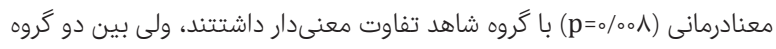

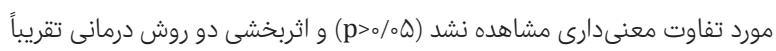
يكسان بود.

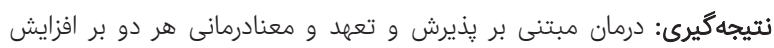

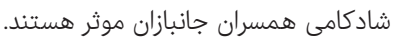
كليدواثهها: درمان مبتنى بر يذيرش و تعهراند، معنادرمانى، شادكامى، همسران، جانبازان

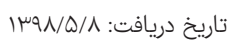

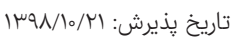

"نويسنده مسئول: ashafiabady@yahoo.com

اثرات آسيبها و فشارهاى روانى ناشى از جنگ روى خانواده و

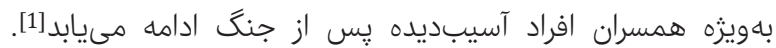

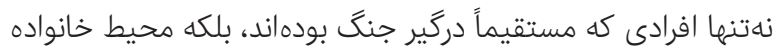

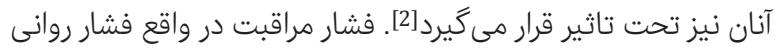


است. روح ضرورتاً يك مفهوم مذهبى نيست، بلكه مانند بدن و ذهن

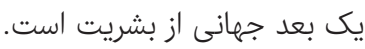

ب) زندگى تحت هر شرايطى حتى در بدبختىهاى بزرگ داراى

معناست.

ج) افراد ميل به معناخواهى دارند كه نخستين انكَيزه براى زندگى و و

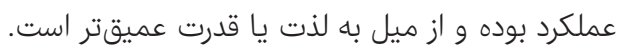

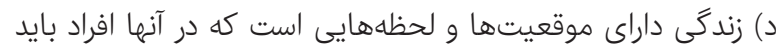

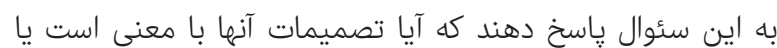

ه) هر فردى منحصر به فرد است و داراى اهميتى غيرقابل جايكزين

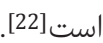

در اين رويكرد درمانى بيمار در جهتى راهنمايى مىشود كه معناى

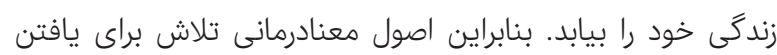

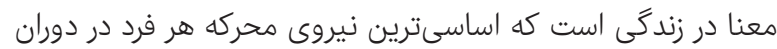

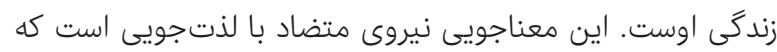

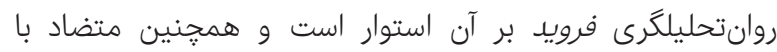

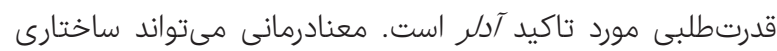

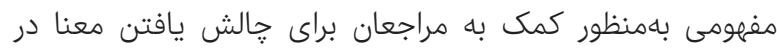

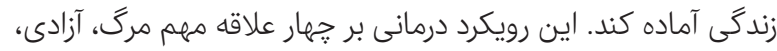

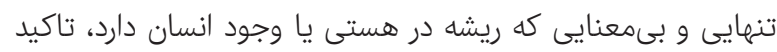

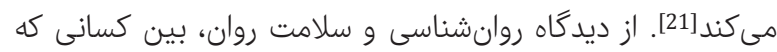
زندخى را معنىدار ادراك مى كنند و كسانى كه مفهوم و مبنايى براى إنى

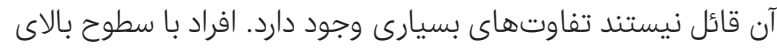

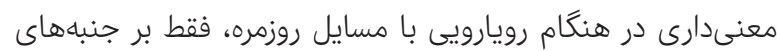
مشخصى از مشكل تمركز مى كنند، در صورتى كه اشخاص با با سطوح

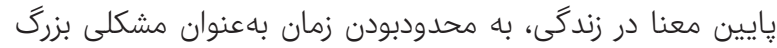

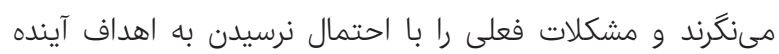

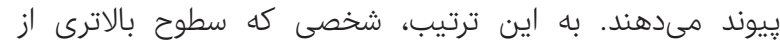

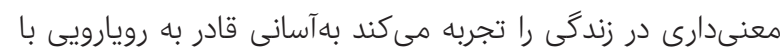

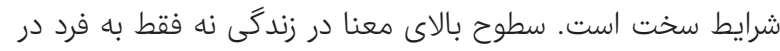

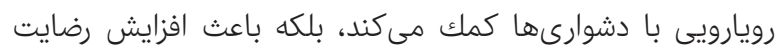

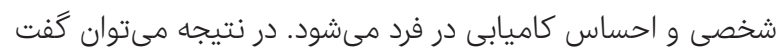

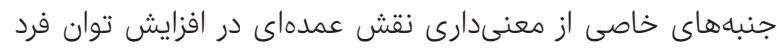

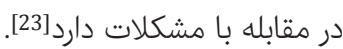

يزوهشهاى انجامشده نشان مىدهند كه درمان مبتنى بر يذيرش

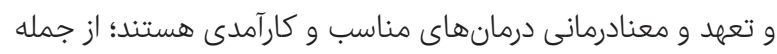

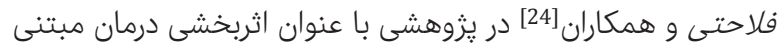

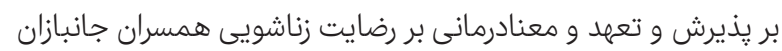

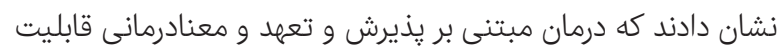
افزايش رضايت زناشويى همسران جانبازان را دارند. هنربيروران در بردئن

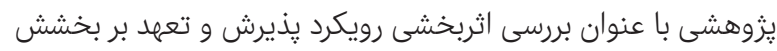

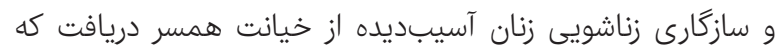

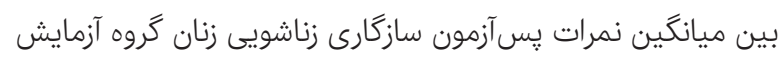

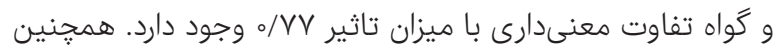

سازكارى اعضاى خانواده را افزايش دهد، بيش از بيش احساس

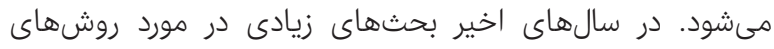

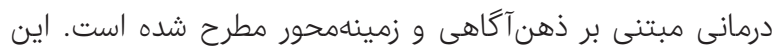

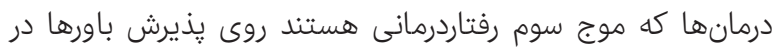

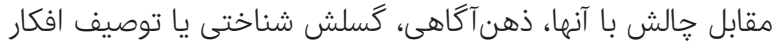

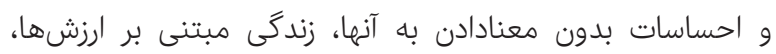

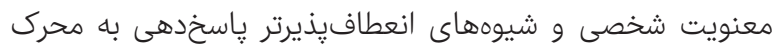

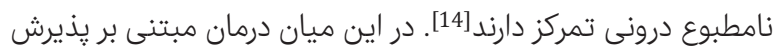

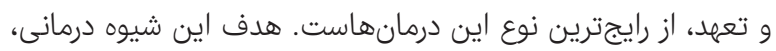

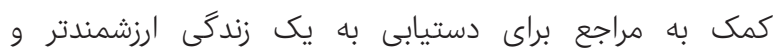

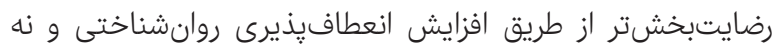

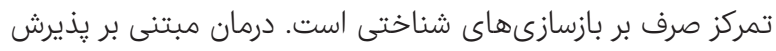

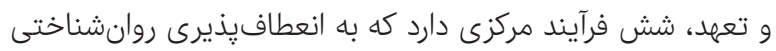

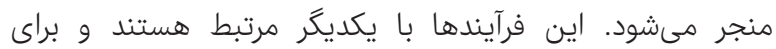

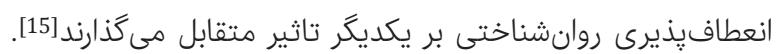

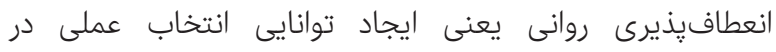

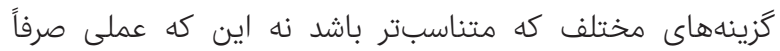
بهمنظور اجتناب از افكار، احساسات، خاطرهها يا تمايلات آشفتلهساز

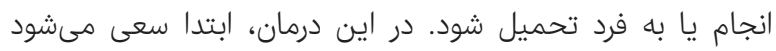

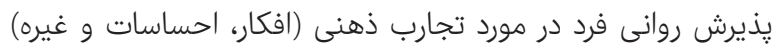

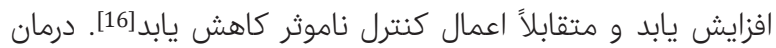

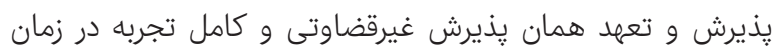

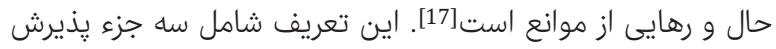

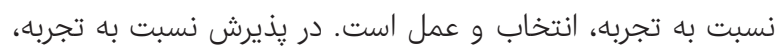

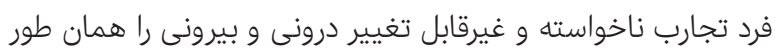

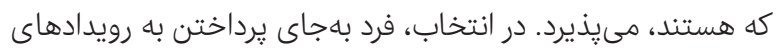

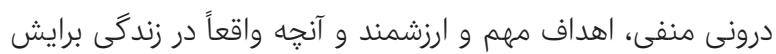

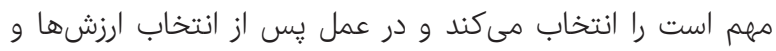

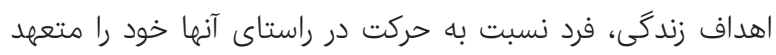

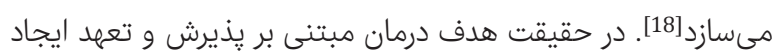

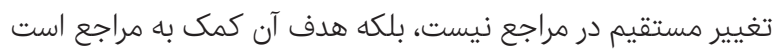

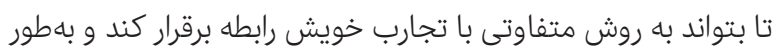

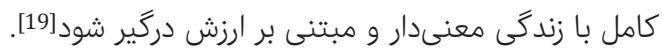

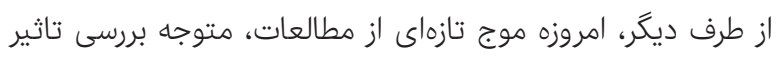

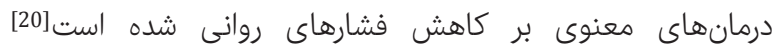

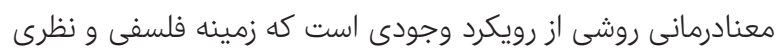

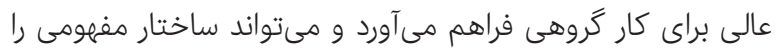

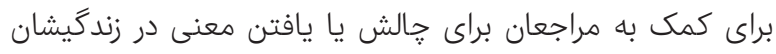

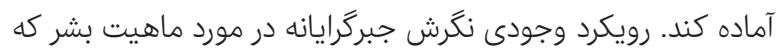

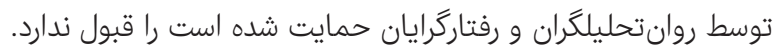

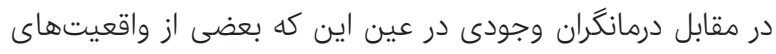

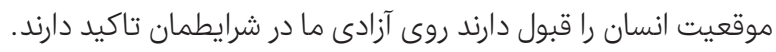

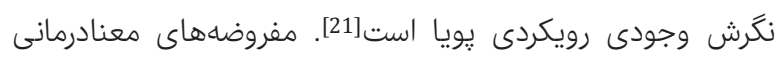

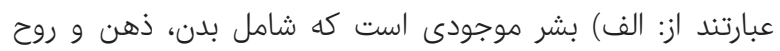


زندگى، شركت در فعاليتهاى اجتماعى و ورزشى و حمايت

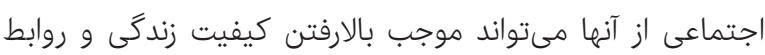
زناشويى همسران جانباز شود[32].

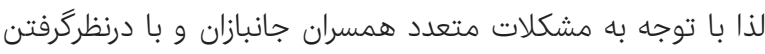

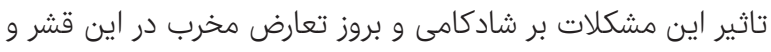

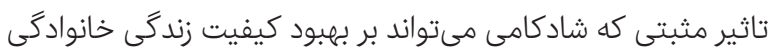

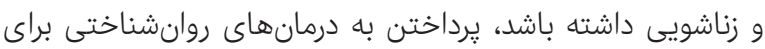

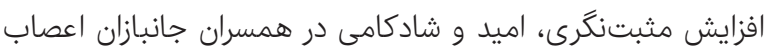

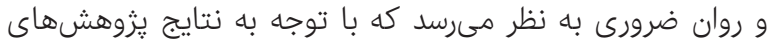

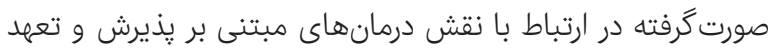

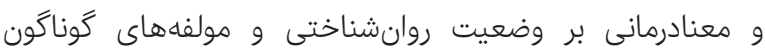
روانشناختى، يزوهش حاضر با هدف بررسى اثربخشى دردئ درمان مبتنى

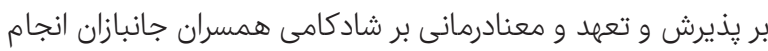

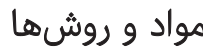

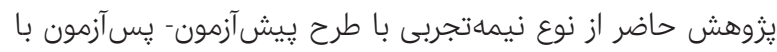

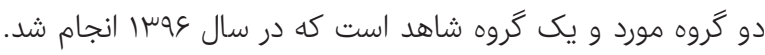

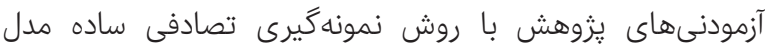

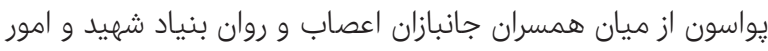

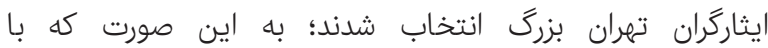

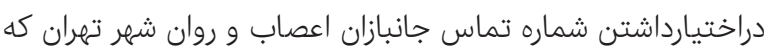

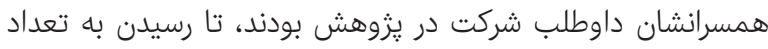

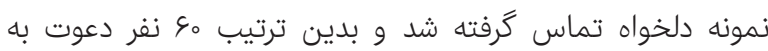

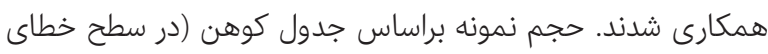

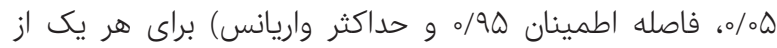

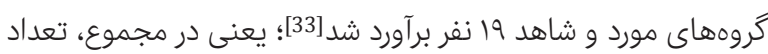

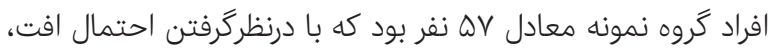

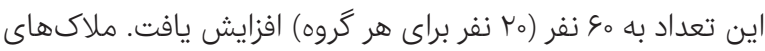

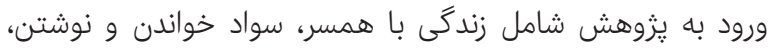

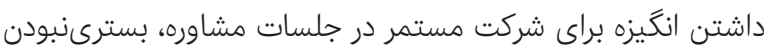

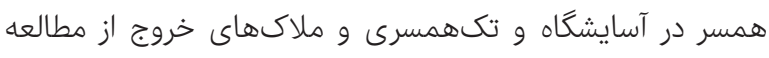
غيبت بيش از يك جلسه، مخدوشبودن קِاسخنامه، قرارداشتن

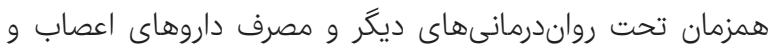

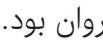

از يرسشنامه اطلاعات جمعيتشناختى شامل اطلاعات مرتبط با

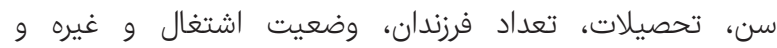

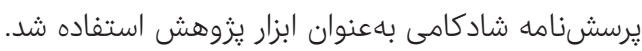

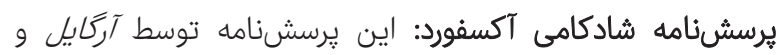

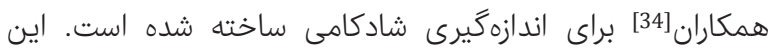

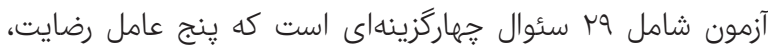

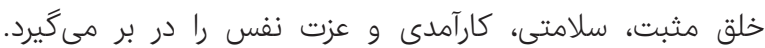

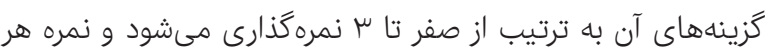

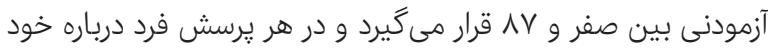

نتايج يزوهش نشان داد كه اثرات درمانى اين رويكرد در ييكيرى نيز

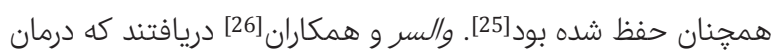

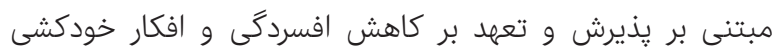

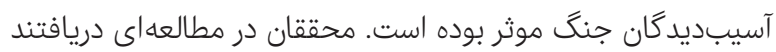

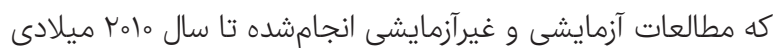

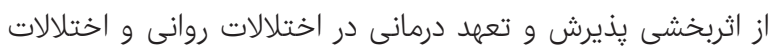

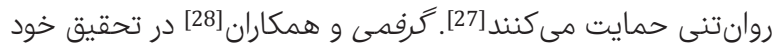

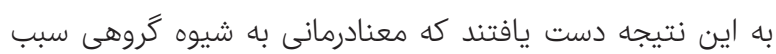

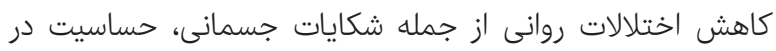

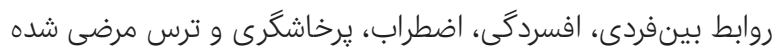

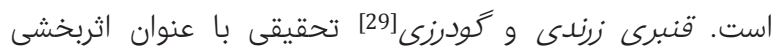

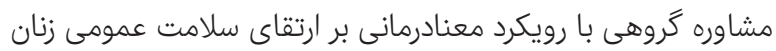

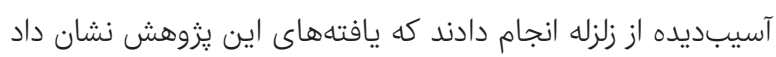

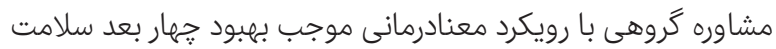

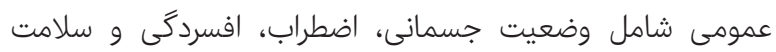
روانى شده است، اما در بعد كاركرد اجتماعى تفاوت معنى معنى أفارى

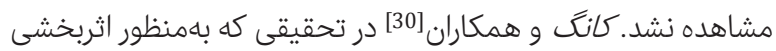

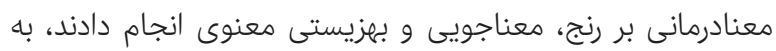

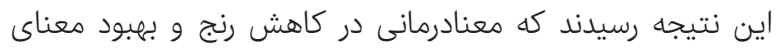

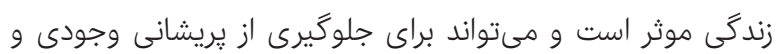

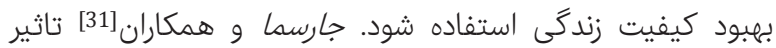

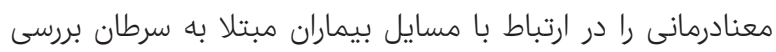

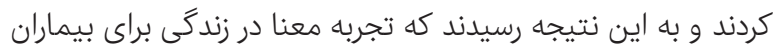

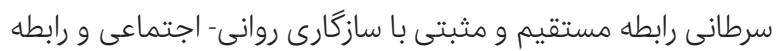

منفى با استرس دارد. توجه به جانبازان جنغ تحميلى و همسران آنها كه بهطور مداوم با

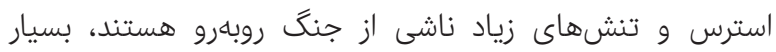

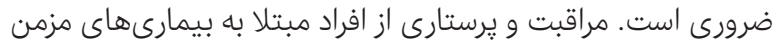

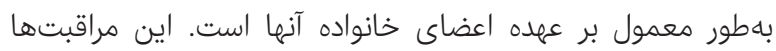

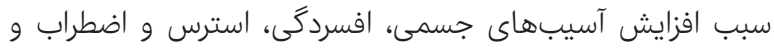

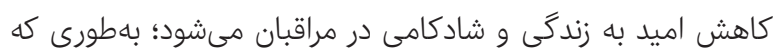

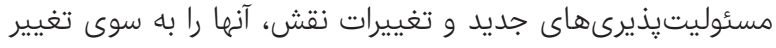

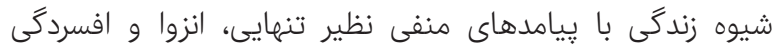

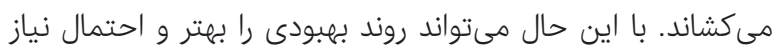

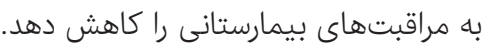

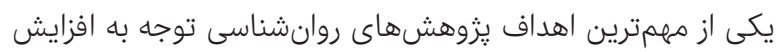

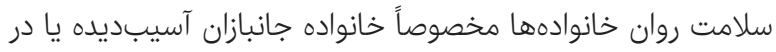
معرض خطر است. زنان بهعنوان كليدىترين عنصر هر خانوانواده نقان

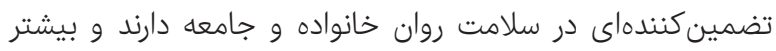

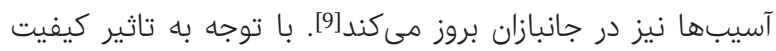

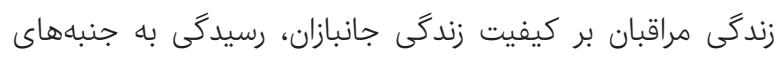

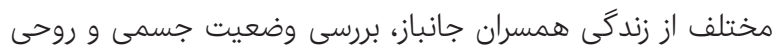
آنان، برطرفكردن مشكلات بهوجودآمده در اثر مراقبت ازيت ازئ جانبازي

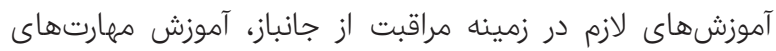




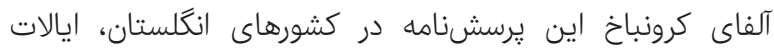

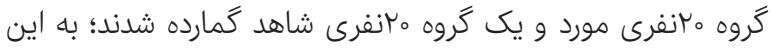

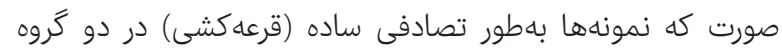

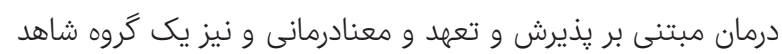

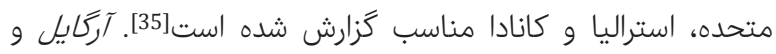

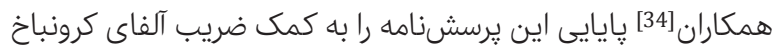

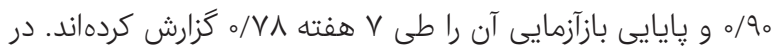
جايكزين شدند. هر كدام از دو گروه مورد، درمان را بهصورت گروهى، توسط يزوهشگ

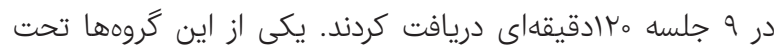

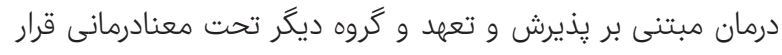

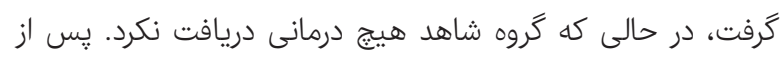

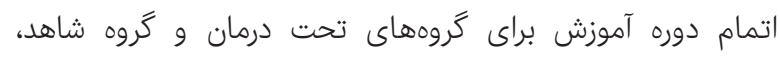

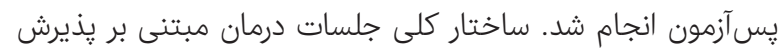

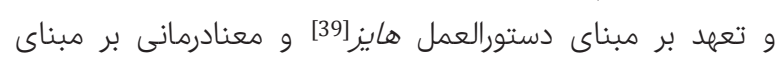
دستوالعمل فرانكل [40] تدوين شد (جدول مبنول هائول

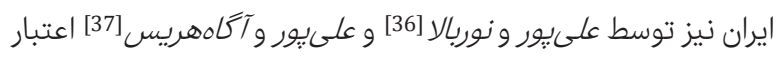

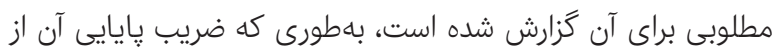

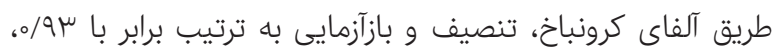

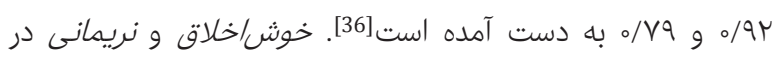

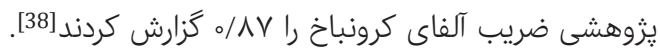

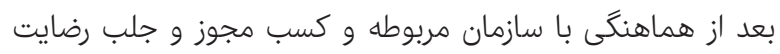

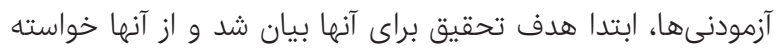

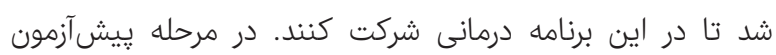

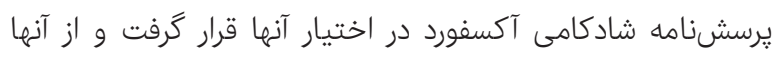

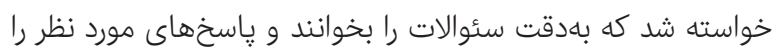

جدول ا) خلاصه محتواى جلسات درمانى اجراشده براى همسران جانبازان

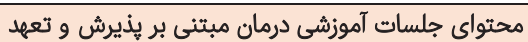

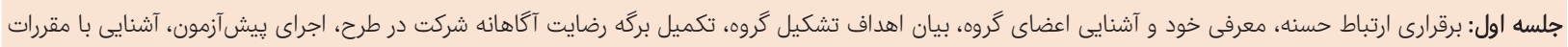

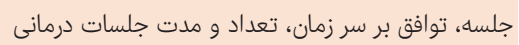

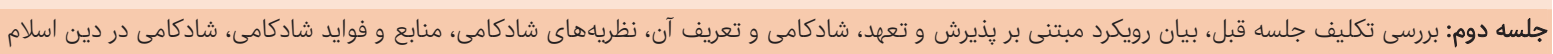

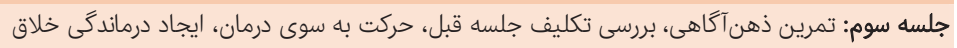

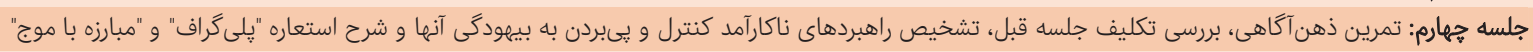

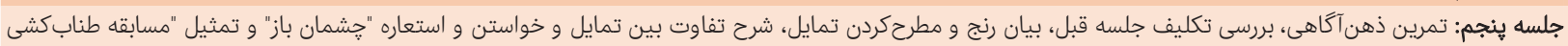
با هيولا"

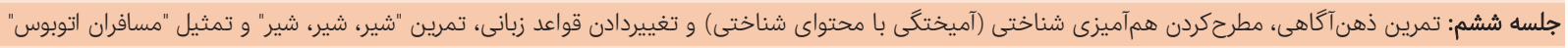

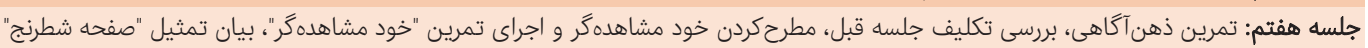

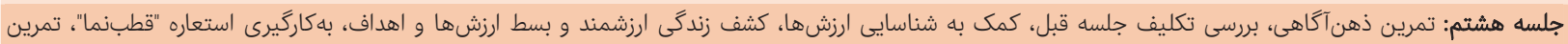

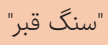

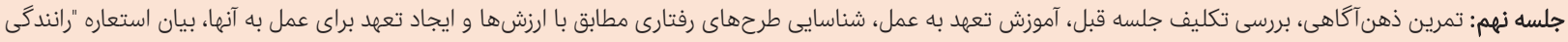

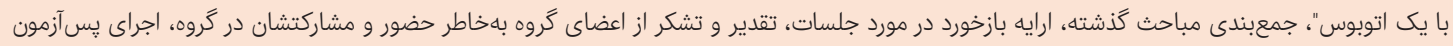

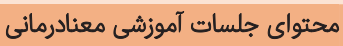

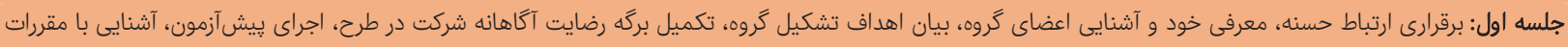

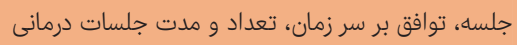

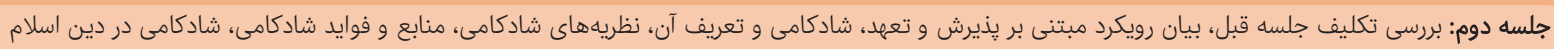

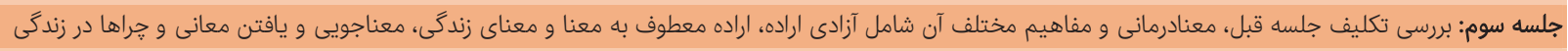

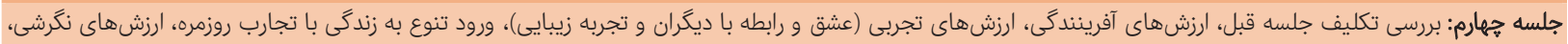

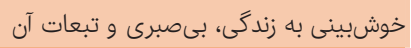

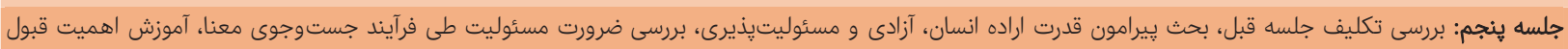

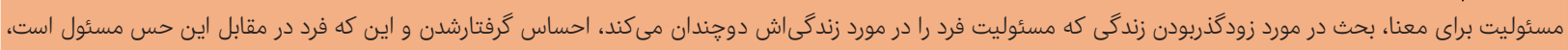

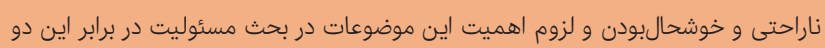

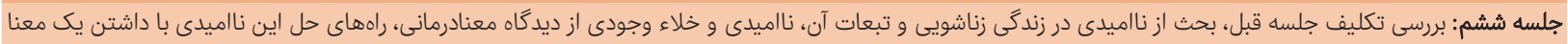

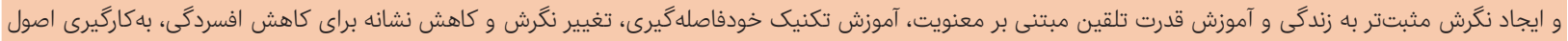

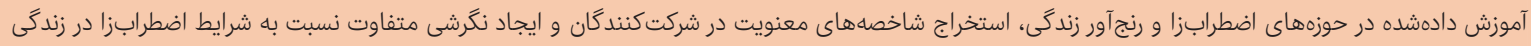

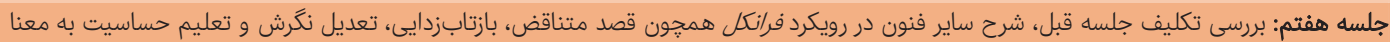

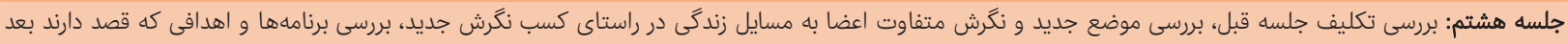

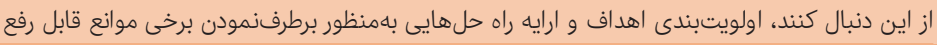

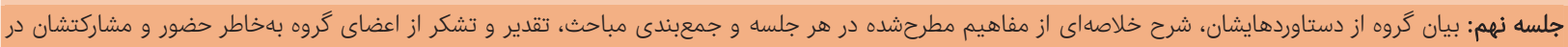

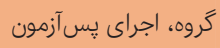


در گروه معنادرمانى و گروه شاهد راهنمايى بود. بيشترين سطح

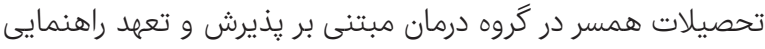

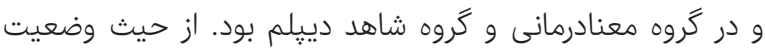

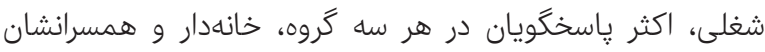

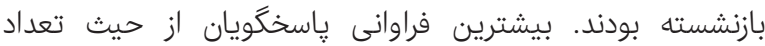

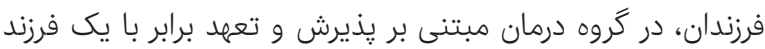

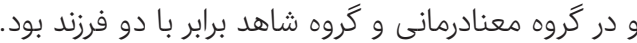

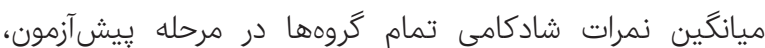
يايينتر از خط برش (ميانگين مورد) بود، ولى ميانگين نمرات

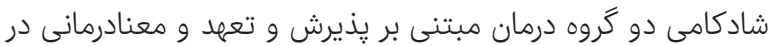

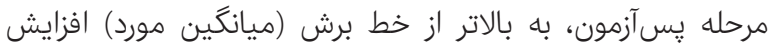

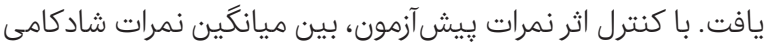

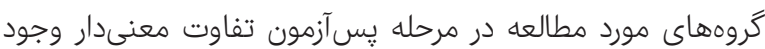

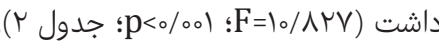

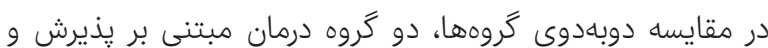

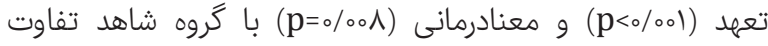

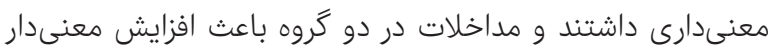

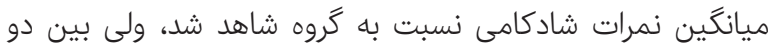

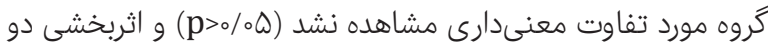

روش درمانى تقريباً يكسان بود (جدول مَّ).
تجزيه و تحليل دادهها به كمك نرمافزار آمارى 18 SPSS و و بان

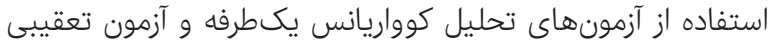

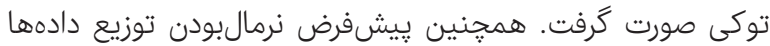

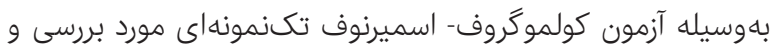
تاييد واقع شد.

\section{يافتهها}

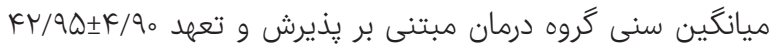
سال، كروه معنادرمانى

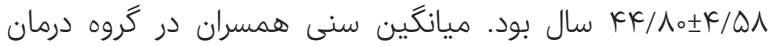

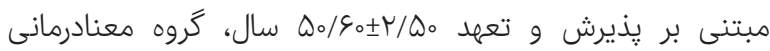
دال

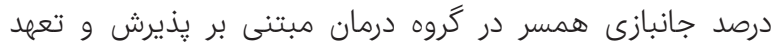

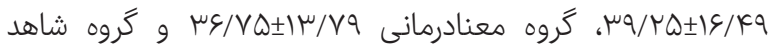

K $K / / D \circ \pm I V / \mu r$

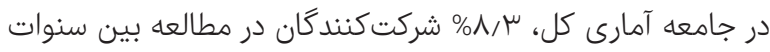

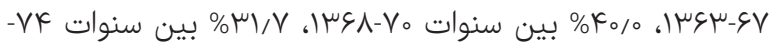

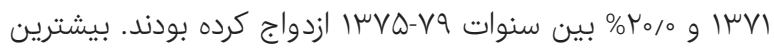

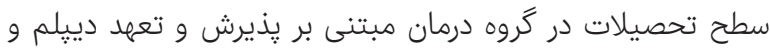

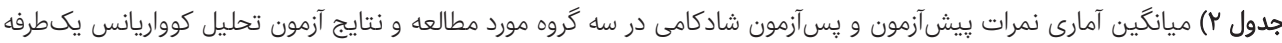

\begin{tabular}{|c|c|c|c|c|}
\hline سطح معنىدارى & Fقدار F F F F F & بس آزمون & ي يش آزمون & كروههاى مورد مطالعه \\
\hline \multirow{3}{*}{$<0 / .01$} & \multirow{3}{*}{ lo/ArV } & $01 / 9_{0} \pm 18 / 90$ & $\mu \varepsilon / \varepsilon \Delta \pm I \mu / \% V$ & گروه درمان مبتنى بر يذيرش و تعهد \\
\hline & & $K \Delta / ৭ \Delta \pm 10 / \Delta V$ & $\mu \Delta / 9 \Delta \pm 11 / V \mu$ & كروه معنادرمانى \\
\hline & & $\mu r / \Lambda \omega \pm \| 1 / \% q$ & $\mu r / \varphi \Delta \pm I r / T F$ & كروه شاهد \\
\hline
\end{tabular}

جدول سا) نتايج آزمون تعقيبى توكى براى مقايسه اختلاف ميانكَينهاى نمرات يسآزمون شادكامى همسران جانبازان اعصاب و روان شهر تهران در كروههاى مورد مطالعه

\begin{tabular}{|c|c|c|c|c|c|}
\hline \multicolumn{2}{|c|}{ 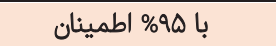 } & \multirow{2}{*}{ سطح معنىدارى } & \multirow{2}{*}{ 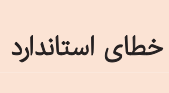 } & \multirow{2}{*}{ تفاوت ميانكين } & \multirow{2}{*}{ كروههاى مورد مطالعه } \\
\hline كرانه بالا & كرانه پايين & & & & \\
\hline$r q / 1 \mu_{0}$ & 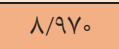 & $\% \% 001$ & $1 / \wedge \wedge \Lambda$ & $19 / \circ \Delta_{\circ}$ & كروه درمان مبتنى بر بذيرش و تعهد با كروه شاهد \\
\hline$r \mu / \Lambda$ 。 & $\mu / \% Y_{\circ}$ & $\% \circ \wedge$ & $1 / 1 \wedge \wedge$ & $1 \% / 100$ & گروه معنادرمانى با گروه شاهد \\
\hline $1 \varepsilon / \mu_{\circ}$ & $-k / \mu$. & $\circ / \mu \mu \gamma$ & $1 / 1 \wedge \Lambda$ & $\Delta / ৭ \Delta_{\circ}$ & گروه درمان مبتنى بر يذيرش و تعهد با كروه معنادرمانى \\
\hline
\end{tabular}

را متوجه زمان حال سازد و بتواند ارزشهاى خود را شناسايى كند و

حتى با وجود افكار و احساسات آزاردهنده، مطابق ارزشها و اهداف

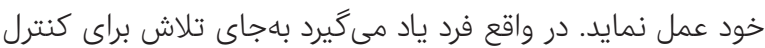
رويدادهاى درونى، آنها را بيذيرد و در جهت رسيدن به اهداف و ارزشهاى خود كام بردارد. بدين ترتيب عملكرد كلى فرد در سطح

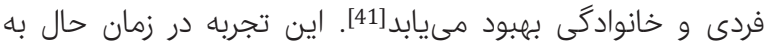

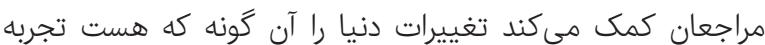

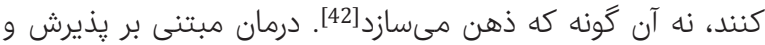

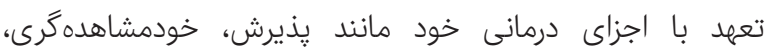

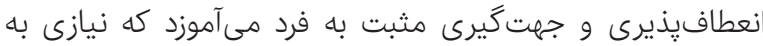

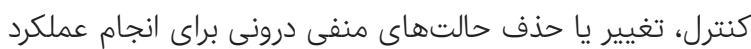

يزوهش حاضر با هدف مقايسه اثربخشى درمان مبتنى بر يذيرش و تعهد و معنادرمانى بر شادكامى همسران جانبازان اعصاب و روان

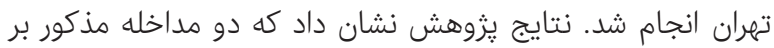

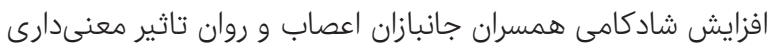
داشته است. در تبيين اثربخشى درمان مبتنى بر رِيرش و تعهل مىتوان گَفت،

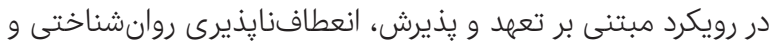

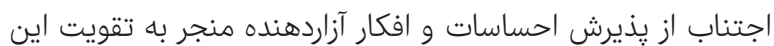

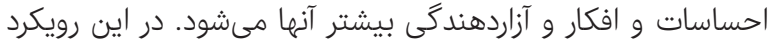

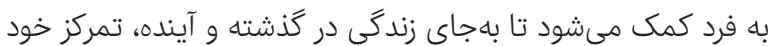




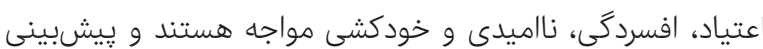

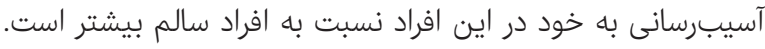

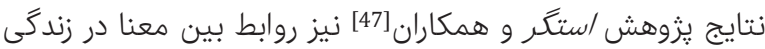
و طيف گستردهاى از سلامت روانى از جمله نشانهائهاى سلامت،

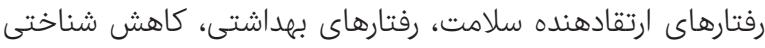

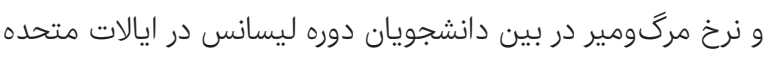

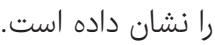
هنكامى كه شخص در خدمت جبهاه

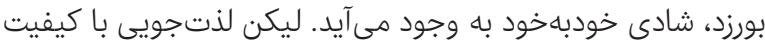

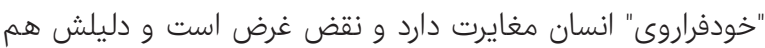

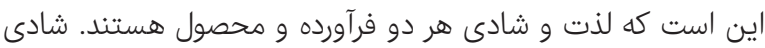

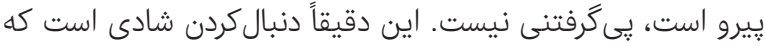

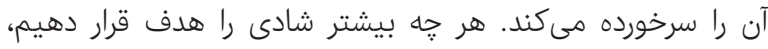

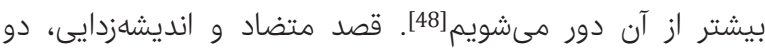

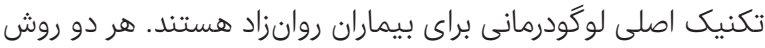

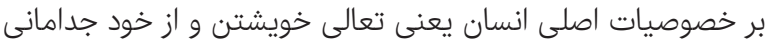

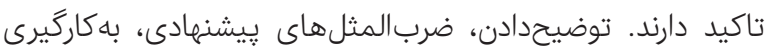

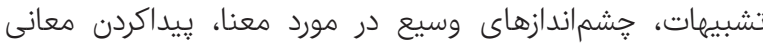

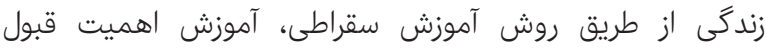

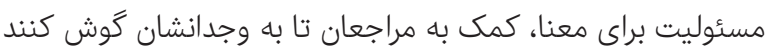

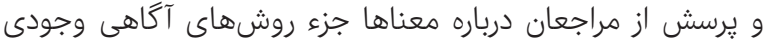

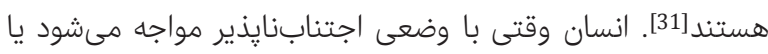

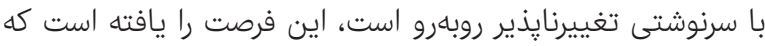

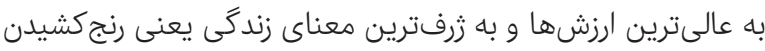

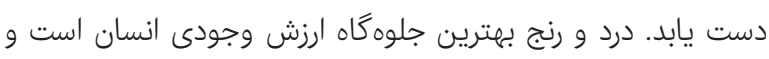

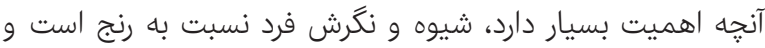
شيوهاى كه اين رنج را به دوش ميكى دشيد.

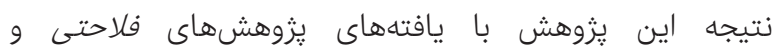

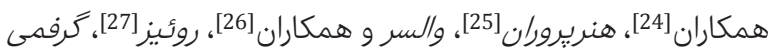

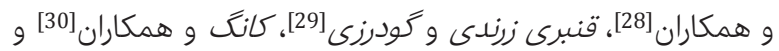

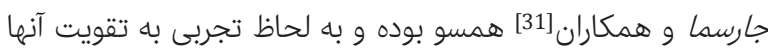

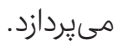
از جمله محدوديتهاى اصلى اين يزوهش مئى متوان به انجامنشدن

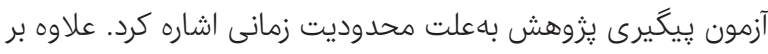

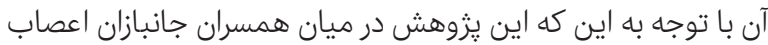

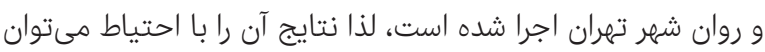
به جامعه آمارى بزرك تر تعميم داد.

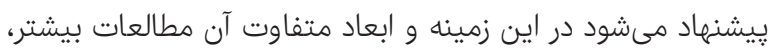

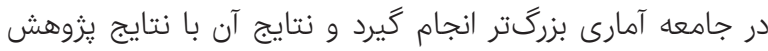

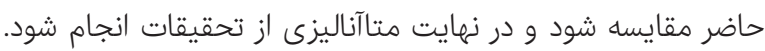

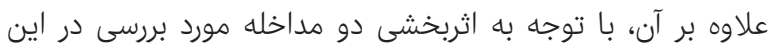

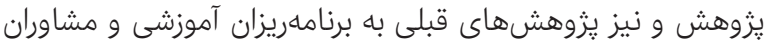

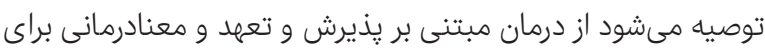

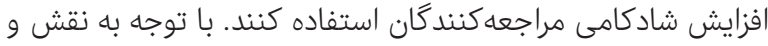

مطلوب ندارد، بلكه بهجاى آن لازم است بر بهبود تمركز، آكاهى و

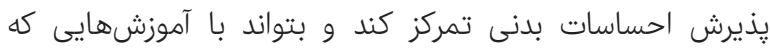

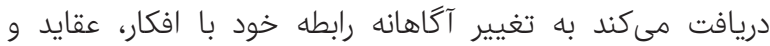

$$
\text { باورهايش بيردازد [17]. }
$$

در جلسات آموزشى درمان مبتنى بر يذيرش وازئ و تعرده، همسران

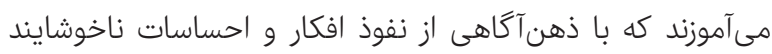
خود بكاهند و بهجاى مبارزه با تجربيات درونى منفىى آنها آنها را بيذيرند.

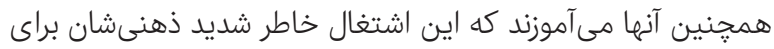

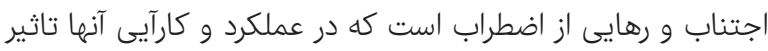

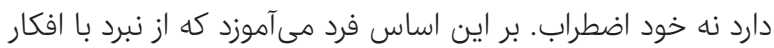

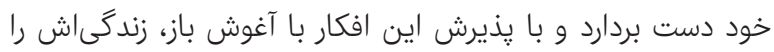

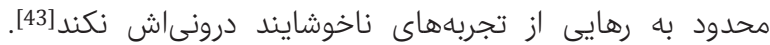

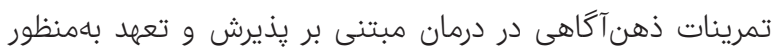

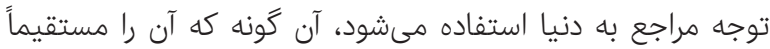
تجربه مى كنند و نه آن گَونه كه با فرآوردههاى ذهنشان آنشان ساخته

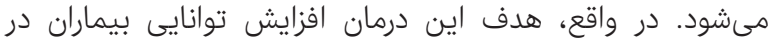

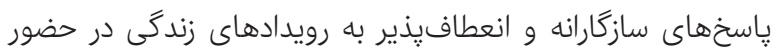

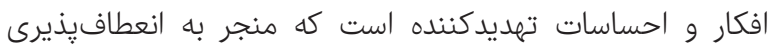

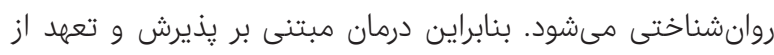

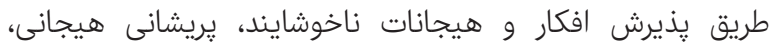

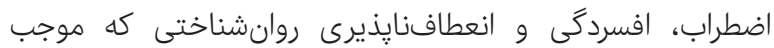

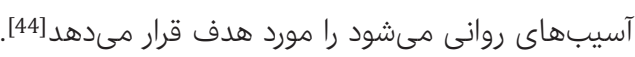

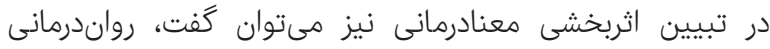

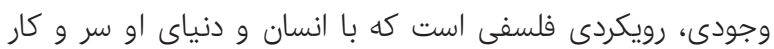

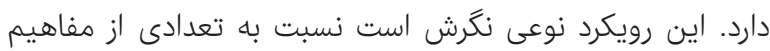

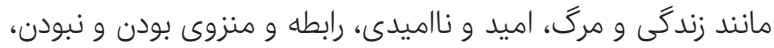

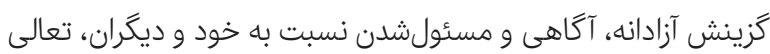

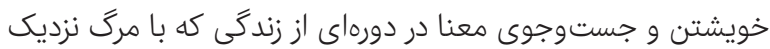
روبهروست. از اين رو مىتوان به بهترين وضع، از آن آن براى بيشبرد

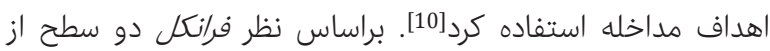

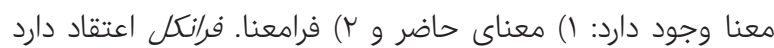

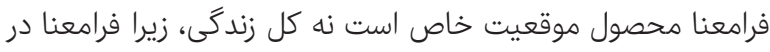

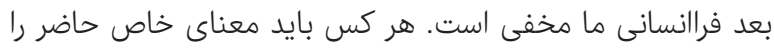

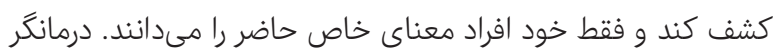
خواستِ مراجع را براى رسيدن به حوزههايى كه معانى در آن بِ بيدا

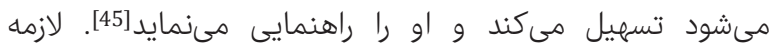
جستوجوى معنا مسئوليت شخصى است. هيج كس و هيج رئ هيز

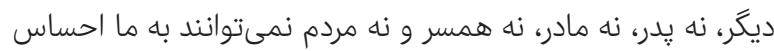

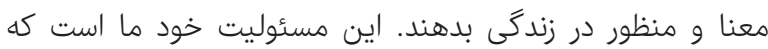

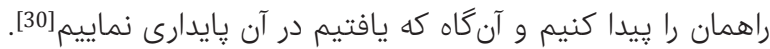

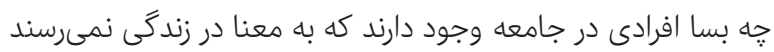

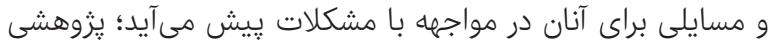

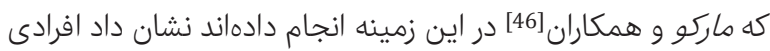
كه در زندگى، معناى كمترى دارند با مشكلات روحى و رو روانى، 
psychiatric ward and their relationship with readmissions. J Fundam Ment Health. 2010;12(45):410-9. [Persian]

6- Khaghanizadeh M, Sirati M. Influence of individual, familial and socioeconomic factors on severity of psychiatric symptoms in veterans with mental disorders. J Mil Med. 2004;6(1):33-7. [Persian]

7- Najafi M, Mohammadifar MA, Dabiri S, Erfani N, Kamari AA. The comparison of the quality of life of the war veterans families with/without post traumatic stress disorder. Iran J War Public Health. 2011;3(3):27-35. [Persian]

8- Hojjat SK, Talebi M, Zamirinejad S, Shakeri M. The effectiveness of training coping styles on combat veterans with PTSD's wives. J North Khorasan Univ Med Sci. 2012;4(2):185-90. [Persian]

9- Khoshakhlagh H, Narimani A. Effectiveness of solutionfocused brief couple therapy on happiness and marital conflict in veterans' spouses. Iran J War Public Health. 2019;11(1):7-13. [Persian]

10- D'raven LL, Pasha-Zaidi N. Happiness strategies among Arab university students in the United Arab Emirates. J Happiness Well-Being. 2014;2(1),131-44.

11- Diener E, Suh EM, Lucas RE, Smith HL. Subjective wellbeing: three decades of progress. Psychol Bull. 1999;125(2):276-302.

12- Luhmann M, Necka EA, Schönbrodt FD, Hawkley LC. Is valuing happiness associated with lower well-being? A factor-level analysis using the Valuing Happiness Scale. J Res Pers. 2016;60:46-50.

13- Nazari A, Goli M. The effects of solution- focused psychotherapy on the marital satisfaction of dual career couples. J Knowledge Health. 2008;2(4):36-40. [Persian] 14- Hayes SC. Climbing our hills: a beginning conversation on the comparison of acceptance and commitment therapy and traditional cognitive behavioral therapy. Clin Psychol. 2008;15(4):286-95.

15- Roditi D, Robinson ME. The role of psychological interventions in the management of patients with chronic pain. Psychol Res Behav Manag. 2011;4:41-9.

16- Hayes SC, Levin ME, Plumb-Vilardaga J, Villatte JL, Pistorello J. Acceptance and commitment therapy and contextual behavioral science: Examining the progress of a distinctive model of behavioral and cognitive therapy. Behav Ther. 2013; 44(2):180-98.

17- Hayes SC, Luoma JB, Bond FW, Masuda A, Lillis J. Acceptance and commitment therapy: model, processes and outcomes. Behav Res Ther. 2006;44(1):1-25.

18- Hayes-Skelton SA, Orsillo SM, Roemer L. An acceptance-based behavioral therapy for individuals with generalized anxiety disorder. Cogn Behav Pract. 2013;20(3):264-81.

19- Hayes SC, Strosahl KD, Bunting K, Twohig M, Wilson KG. What is acceptance and commitment therapy? In: Hayes SC, Strosahl KD, editors. A practical guide to acceptance and commitment therapy. New York: Springer; 2004. p. 3-29.

20- Smit TB, Bartz J, Richards PS. Outcomes of religious and spiritual adaptations to psychotherapy: a meta-analytic review. Psychother Res, 2007;17(6):643-55.

21 - Corey G. Theory and practice in group counseling. $4^{\text {th }}$ Edition. Bostson: Brooks/Cole Publishing Company; 1995.

22- Kim TH, Lee SM, Yu K, Lee S, Puig A. Hope and the meaning of life as influences on Korean adolescents resilience: Implications for counselors. Asia Pacific Educ

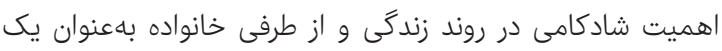

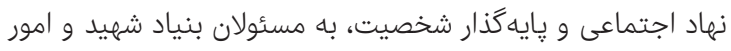

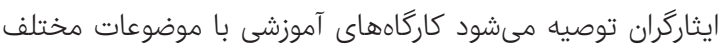

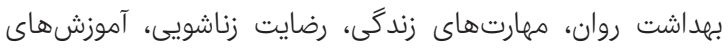

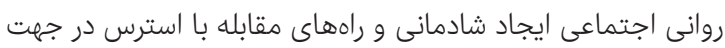

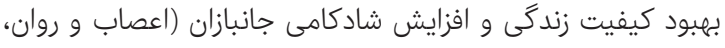

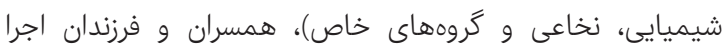

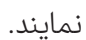

$$
\begin{aligned}
& \text { نتيجه گيرى } \\
& \text { درمان مبتنى بر يذيرش و تعهد و معنادرمانى هر دو باعث افزايش }
\end{aligned}
$$

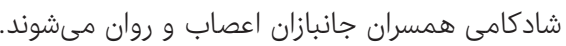

تشكر و قدردانى: از مسئولان و همكاران محترم مركز دانشيزوهان و

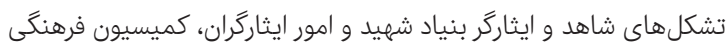

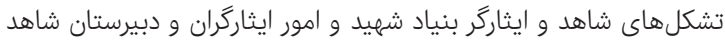

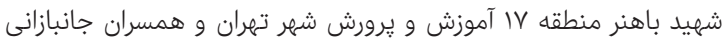

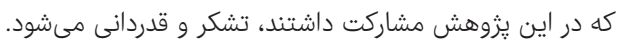

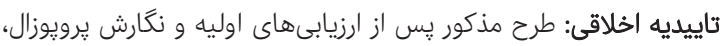

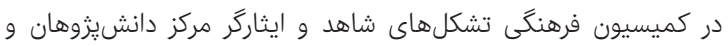

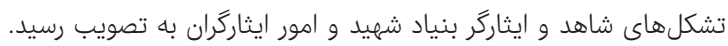

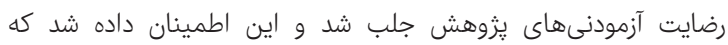

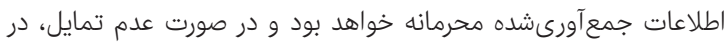

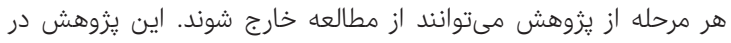

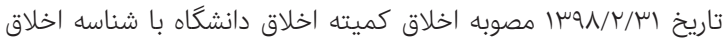
تعافرض IR.IAU.BOJNOURD.REC.1398.006 را دريافت كرده است. تعارض منافع: تعارض منافعى با شخص يا سازمانى وجود ندارد.

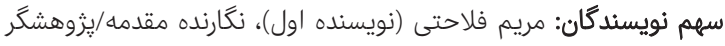

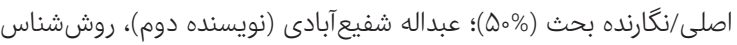

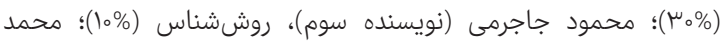

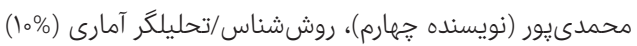
منابع مالى: يزوهش حاضر بخشى از رساله دكترى نويسنده اول بوده است.

1- Dekel R, Monson CM. Military-related post-traumatic stress disorder and family relations: Current knowledge and future directions. Aggress Violent Behav. 2010;15(4):303-9.

2-Saleh S, Zahedi Asl M. Correlation of social support with social health of psychiatry veterans wives. Iran J War Public Health. 2014;6(5):201-6. [Persian]

3- Saban KL, Mathews HL, Janusek LW. The relationship among depression and caregiver burden with salivary cortisol awakening level in female caregivers of stroke survivors. Brain Behav Immun. 2010;24(Suppl 1):S21. 4- Renshaw KD, Rodebaugh TL, Rodrigues CS.

Psychological and marital distress in spouses of Vietnam veterans: Importance of spouses' perceptions. J Anxiety Disord. 2010;24(7):743-50.

5- Manteghi A. Level of expressed emotion, depression and caregiver burden in wives of veterans admitted in 
ها اثربخشى درمان مبتنى بر עذيرش و تعهد و معنادمانى بر شادكامى همسران جانبازان 36-Alipour A, Noorbala A. A preliminary evaluation of the validity and reliability of the Oxford happiness questionnaire in students in the universities of Tehran. Iran J Psychiatry Clin Psychol. 1999;5(1 and 2):55-66. [Persian]

37- Alipour A, Agah Heris M. Reliability and validity of the Oxford happiness inventory among Iranians. J Dev Psychol. 2007;3(12):287-98. [Persian]

38- Khoshakhlagh $\mathrm{H}$, Narimani A. Effectiveness of solution-focused brief couple therapy on happiness and marital conflict in veterans' spouses. Iran J War Public Health. 2019;11(1):7-13. [Persian]

39- Hayes SC. Acceptance and commitment therapy, relational frame theory, and the third wave of behavioral and cognitive therapies. Behav Ther. 2004;35(4):639-65. 40- Frankle VE. Man's search for meaning: an introduction to logotheraphy. NewYork: Pocket Books; 1963.

41- Azizi A, Ghasemi S. Comparison the effectiveness of solution-focused therapy, cognitive-behavior therapy and acceptance and commitment therapy on depression and quality of life in divorced women. Cult Couns Psycother. 2017;8(29):207-36. [Persian]

42- Masuda A, Hayes SC, Sackett CF, Twohig MP. Cognitive defusion and self-relevant negative thoughts: examining the impact of a ninety year old technique. Behav Res Ther. 2004;42(4):477-85.

43- Bernier M, Thienot E, Codron R, Fournier JF. Mindfulness and acceptance approaches in sport performance. J Clin Sports Psychol. 2009;4(4):320-33. 44- Moghtadayi M, Khoshakhlagh H. Effectiveness of acceptance- and commitment-based therapy on psychological flexibility of veterans' spouses. Iran J War Public Health. 2015;7(4):183-8. [Persian]

45- Wong PTP. Meaning of life and meaning of death in successful aging. In: Tomer A, editor. Death attitudes and the older adult. New York, NY: Brunner/Mazel Publishers; 2000. p. 23-35.

46- Marco JH, Garcia-Alandete J, Pérez S, Guillen V, Jorquera M, Espallargas P, Botella C. Meaning in life and non-suicidal self-injury: A follow-up study with participants with borderline personality disorder. Psychiatry Res. 2015;15:230(2):561-6.

47- Steger MF, Fitch-Martin AR, Donnelly J, Rickard KM. Meaning in Life and Health: Proactive health orientation links meaning in life to health variables among American undergraduates. J Happiness Stud. 2015;16:583-97.

48- Jim HS, Richardson SA, Golden-Kreutz DM, Andersen BL. Strategies used in coping with a cancer diagnosis predict meaning in life for survivors. J Health Psychol. 2006;25(6):753-61.
Rev. 2005;6(2);143-52.

23- Barnes RC. Victor Frankl's logotherapy: spirituality and meaning in the new millennium. TCA J. $2000 ; 28(1): 24-31$.

24- Falahati M, Shafiabadi A, Jajromi M, Mohammadipour M. Effectiveness of acceptance and commitment therapy and logotherapy on marital satisfaction of veterans' spouses. Iran J War Public Health. 2019;11(3):139-45. [Persian]

25- Honarparvaran N. The Efficacy of acceptance and commitment therapy (ACT) on forgiveness and marital adjustment among women damaged by martial infidelity. J Soc Women. 2014;5(3):135-50. [Persian]

26- Walser RD, Garvert DW, Karlin BE, Trockel M, Ryu DM, Taylor CB. Effectiveness of acceptance and commitment therapy in treating depression and suicidal ideation in veterans. Behav Res Ther. 2015;74:25-31.

27- Ruiz FJ. A review of acceptance and commitment therapy (ACT) empirical evidence: correlational, experimental psychopathology, component and outcome studies. Int J Psychol Psychol Ther. 2010;10(1):125-62.

28- Gerfami H, Shafiabadi A, Sanai Zaker B. The effectiveness of group-based logotherapy on reducing mental disorders symptoms in women with breast cancer. Andiseh Va Raftar. 2009;4(13):35-42. [Persian]

29- Ghanbari Zarandi Z, Goudarzi M. The impact of group counseling in logo therapy method the improvement of general health of female victims of earthquake. J Women Stud. 2009;2(4):57-66. [Persian]

30- Kang KA, Im JI, Kim HS, Kim SJ, Song MK, Sim S. The effect of logotherapy on the suffering, finding meaning, and spiritual well-being of adolescents with terminal cancer. J Korean Acad Child Health Nurs. 2009;15(2):13644.

31- Jaarsma TA, Pool G, Ranchor AV, Sanderman R. The concept and measurement of meaning in life in Dutch cancer patient. Psychooncology. 2007;16(3):241-8.

32- Han B, Haley WE. Family caregiving for patients with stroke: Review and analysis. Stroke. 1999;30(7):1478-85. 33- Cristofolini L, Testoni M. The importance of sample size and statistical power in experimental research: a comparative study. Acta Bioeng Biomech. 2000;2(1):3-16. 34- Argyle M, Martin M, Crossland J. Happiness as a function of personality and social encounters. In: Forgas JP, Innes JM, editors. Recent advances in social psychology: an international perspective. New York: North Holland: Elsevier Science Publishers; 1989. p. 189247.

35- Gong M. Does status in consistency matter for marital quality? J Fam Issues. 2007;28(12):1582-610. 